\title{
INVESTIGATING A DATED PIECE OF THE SHROUD OF TURIN
}

\author{
Rachel A Freer-Waters \\ Arizona State Museum, University of Arizona, Tucson, Arizona 85721, USA.
}

A J Timothy Jull

NSF Arizona AMS Laboratory, University of Arizona, Tucson, Arizona 85721, USA; Also: Department of Geosciences, University of Arizona, Tucson, Arizona 85721, USA. Corresponding author. Email: jull@email.arizona.edu.

\begin{abstract}
We present a photomicrographic investigation of a sample of the Shroud of Turin, split from one used in the radiocarbon dating study of 1988 at Arizona. In contrast to other reports on less-documented material, we find no evidence to contradict the idea that the sample studied was taken from the main part of the shroud, as reported by Damon et al. (1989). We also find no evidence for either coatings or dyes, and only minor contaminants.
\end{abstract}

\section{INTRODUCTION}

Une image vaut mieux que mille mots (proverb).

The Shroud of Turin is a controversial cloth with a human image visible on the surface (Walsh 1963). Many different specialists using many various techniques and tools have analyzed the Shroud of Turin, in particular an extensive study done in 1978 (Schwalbe and Rogers 1982). In 1988, the University of Arizona's Accelerator Mass Spectrometry (AMS) Laboratory was one of the three groups that measured the radiocarbon date of the shroud to be medieval (Damon et al. 1989), stating that "the age of the shroud is obtained as AD 1260-1390, with at least 95\% confidence."

There have been many reports (too numerous to list here) that questioned various aspects of the dating measurement, but none of these were sufficient to challenge the ${ }^{14} \mathrm{C}$ dating measurement itself. An excellent summary of these questions is given by Currie (2004) and others. Some of these challenges can be described as "creative hypotheses" including irradiation of the shroud, isotopic fractionation, or exchange during fire and non-contemporaneous coatings. Other reports challenged the provenance of the sample itself, which if true could undermine the confidence of the ${ }^{14} \mathrm{C}$ result if the sample can be called into question (e.g. Brown 2005; Rogers 2005; Benford and Marino 2008). An excellent objective technical description of the shroud, its possible origins and weaving technologies, is given by Tyrer (1981), to which we refer the reader.

We therefore undertook this study to characterize more carefully the sample used for ${ }^{14} \mathrm{C}$ dating of the shroud at Arizona for the following reasons: to see if we could confirm that the dated sample is consistent with the rest of the cloth, and to assess the possibility of contaminants that might have affected the ${ }^{14} \mathrm{C}$ age. Our purpose is to describe the textile's visible properties, for the record, so that there will be no question as to the nature of the sample that was ${ }^{14} \mathrm{C}$ dated.

\section{METHODS}

The weave structure of the textile fragment was analyzed using low magnification. Ann Hedlund, director of the Gloria F Ross Center for Tapestry Studies, was also consulted on the weave structure of the fragment. Low magnification $(\sim 30 \times)$ observation of the entire fragment was done under a stereomicroscope. Standard fabric analysis procedures were used as the basis to quantify the textile properties of this fragment. Fiber identification was done using high magnification (320×), viewed through both transmitted light and polarized light with an Olympus BX-51 microscope. The fibers were also viewed with epifluorescence microscopy, also on the Olympus BX-51. Six samples were taken from the warp and weft fibers at different locations on a fragment remaining from the ${ }^{14} \mathrm{C}$ study in 1988. This fragment, labeled A1B, is approximately $0.5 \times 1 \mathrm{~cm}$ and originally weighed $12.39 \mathrm{mg}$. 


\section{RESULTS}

Low magnification was used to observe the weave structure, yarn characteristics, and general surface properties. The yarns of both the warp and weft are single yarns, and both are twisted in the zdirection (Emery 1980). The warp has a high degree of twist in the yarn with irregularities common in hand-spun yarns, and the weft has a comparatively lower twist. Analysis of the weave structure of this particular fragment revealed a 3/1-twill weave. This type of uneven twill can be confusing because the two sides of the textile are not identical. This is consistent with the rest of the Shroud of Turin (Tyrer 1981). The warp fabric count is 30 yarns per $\mathrm{cm}$ (76 per inch) and the weft is 40 yarns per cm (102 per inch), creating an unbalanced weave. The thickness of the textile is $\sim 250 \mu \mathrm{m}$. No coatings were visible at this level of magnification, only usual types of surface debris to be expected. Figure 1 shows an example of foreign material loosely adhered to the surface, but not visible to the naked eye.

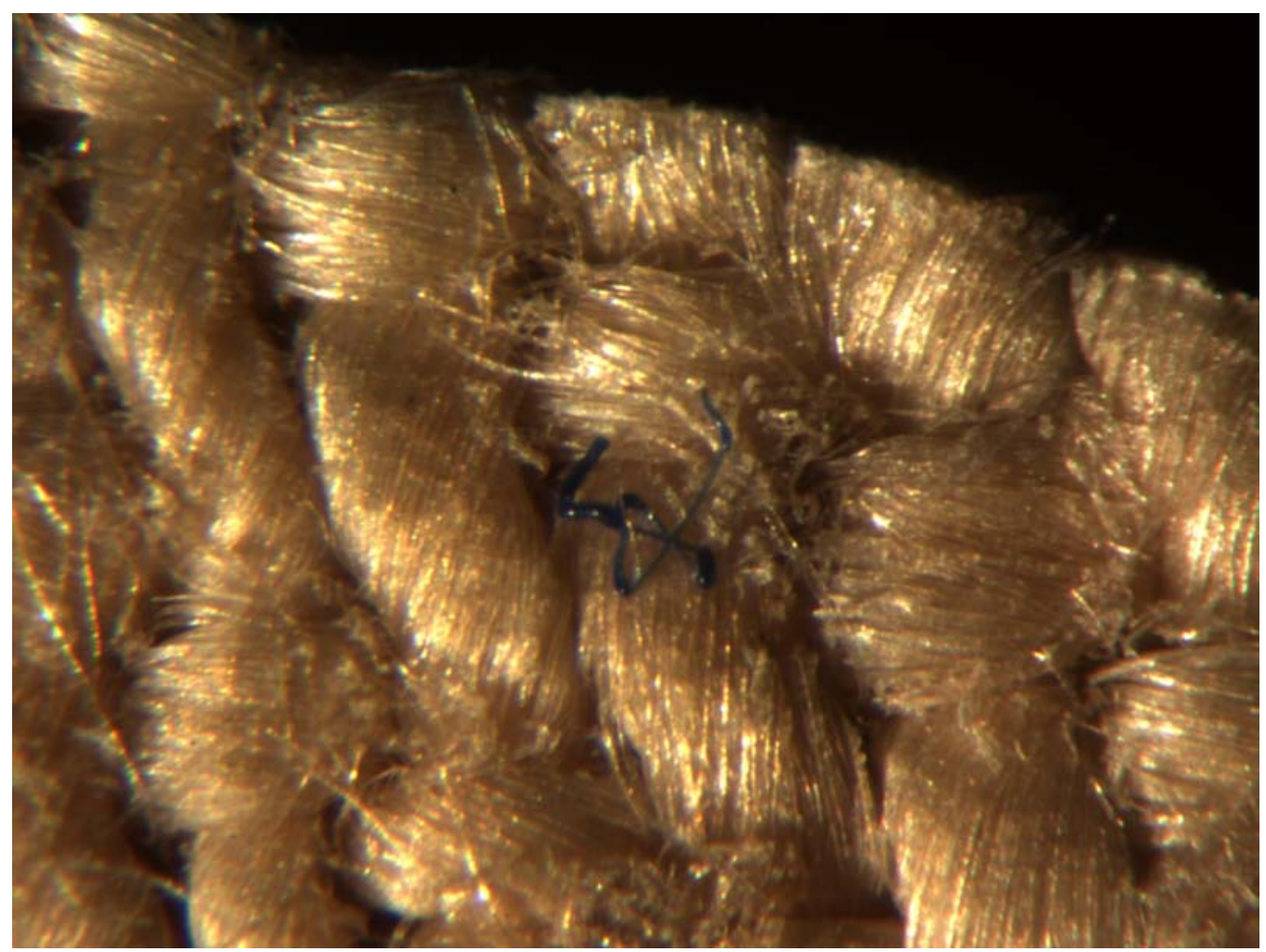

Figure 1 Low-magnification close-up of the shroud textile, showing an example of some foreign material (apparently wax) adhering to the surface. Horizontal scale is $\sim 0.18 \mathrm{~cm}$, corresponding to $\sim 7$ weft threads. Note the 3:1 weave pattern.

The fiber content is linen, a bast fiber from the cultivated plant Linum usitatissimum (Florian 1990), as shown in Figure 2. The diameters of ultimate fibers are consistent with surveys of Linum fiber widths (Catling and Grayson 1982; Garside and Wyeth 2006). Most of the fibers sampled have a diameter at the narrower end of the spectrum, at $\sim 11 \mu \mathrm{m}$ (see Figure 3). The reason for the narrow fiber diameter might be simply related to the initial harvesting and processing of linen fiber, or the age of the fibers. The fiber content of the textile from which this fragment was taken is undoubtedly linen. 


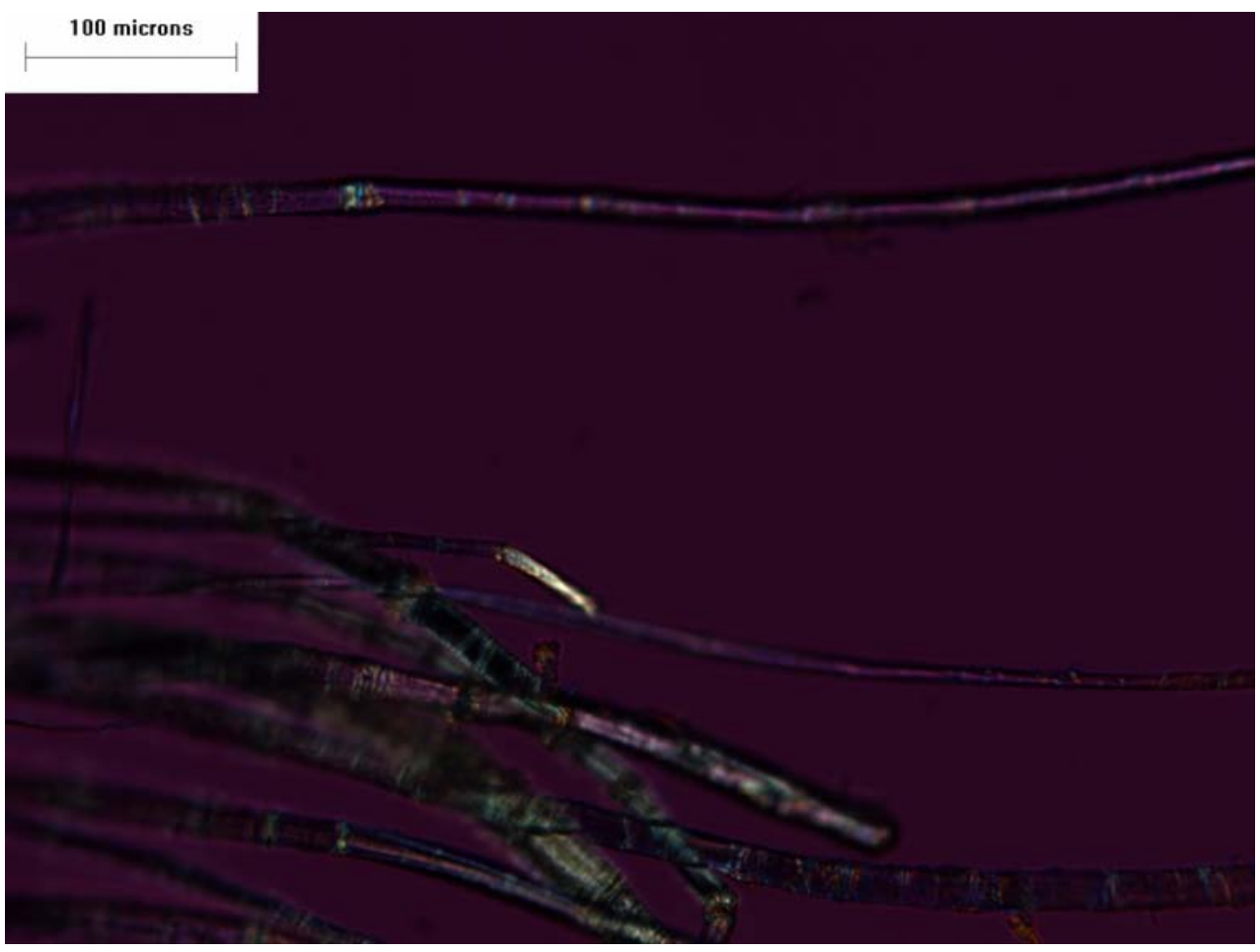

Figure 2 High-magnification image of linen fibers, with crossed-polarized light and $530 \mathrm{~nm}$ compensation

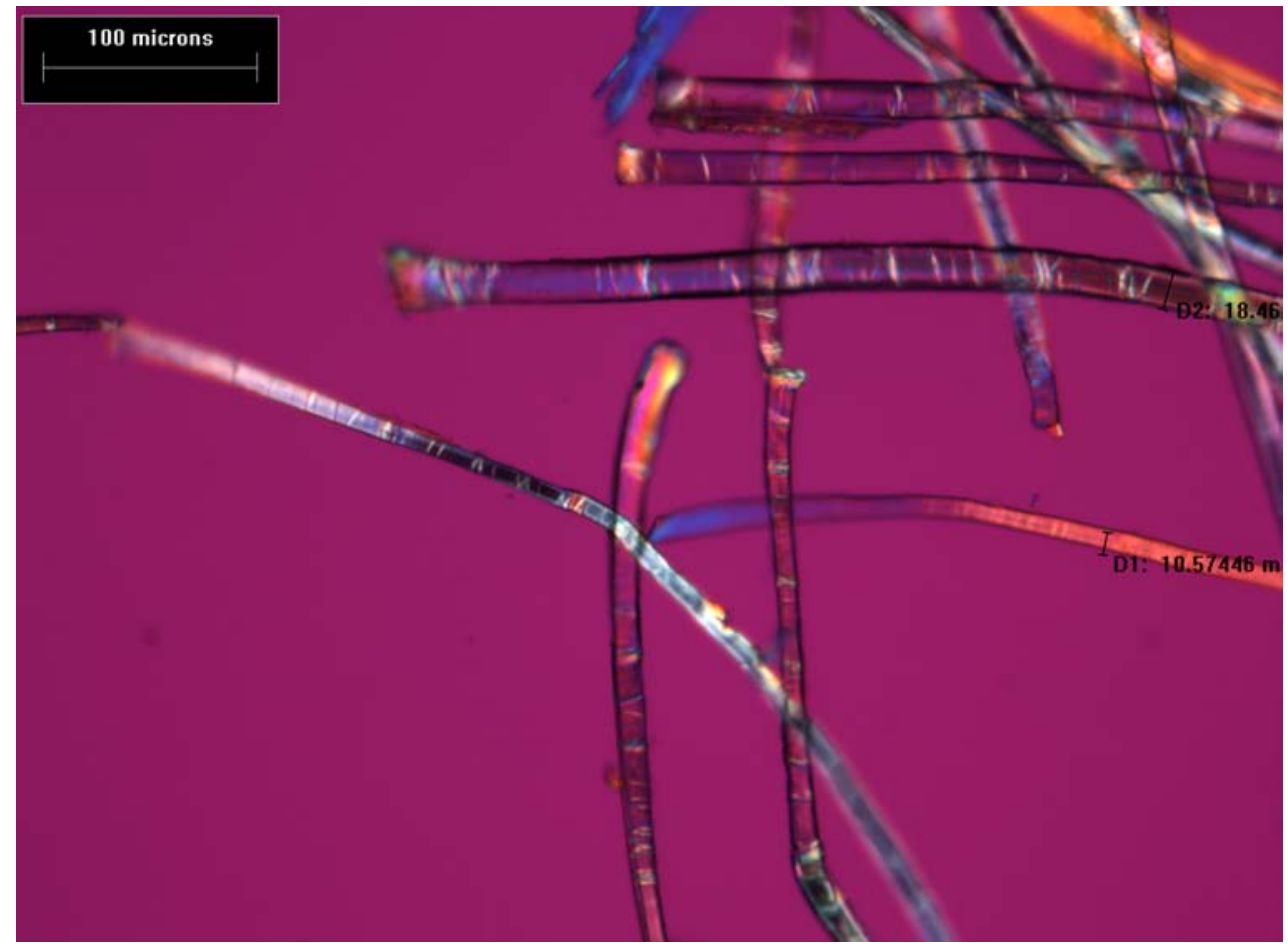

Figure 3 High-magnification image of linen fibers, crossed polars and $530 \mathrm{~nm}$ compensation, showing the thickness of the individual fibers. 
Cotton fibers were observed on three occasions, with one isolated shown in Figure 4. In one case, we were unable to determine whether a cotton fiber as observed within a bundle of fiber still partially intact from the yarn structure or whether this is surface contamination, as shown in Figure 5. This image also shows another possible cotton fiber, some severely damaged unidentifiable fibers, and general debris, indicating this area was more exposed and more vulnerable to loose contamination. Under UV fluorescence, the fibers fluoresce uniformly and do not show any indication of an overall coating. A good example of this behavior is given in Figure 6. In a few places, mold spores are visible, and the spores and the surrounding regions fluoresce more brightly (see Figure 7). Small dark spots were visible in small quantities and do not reflect at all under UV light, which leads us to believe these are small iron oxide particles (Morris et al. 1980; Schwalbe and Rogers 1982).

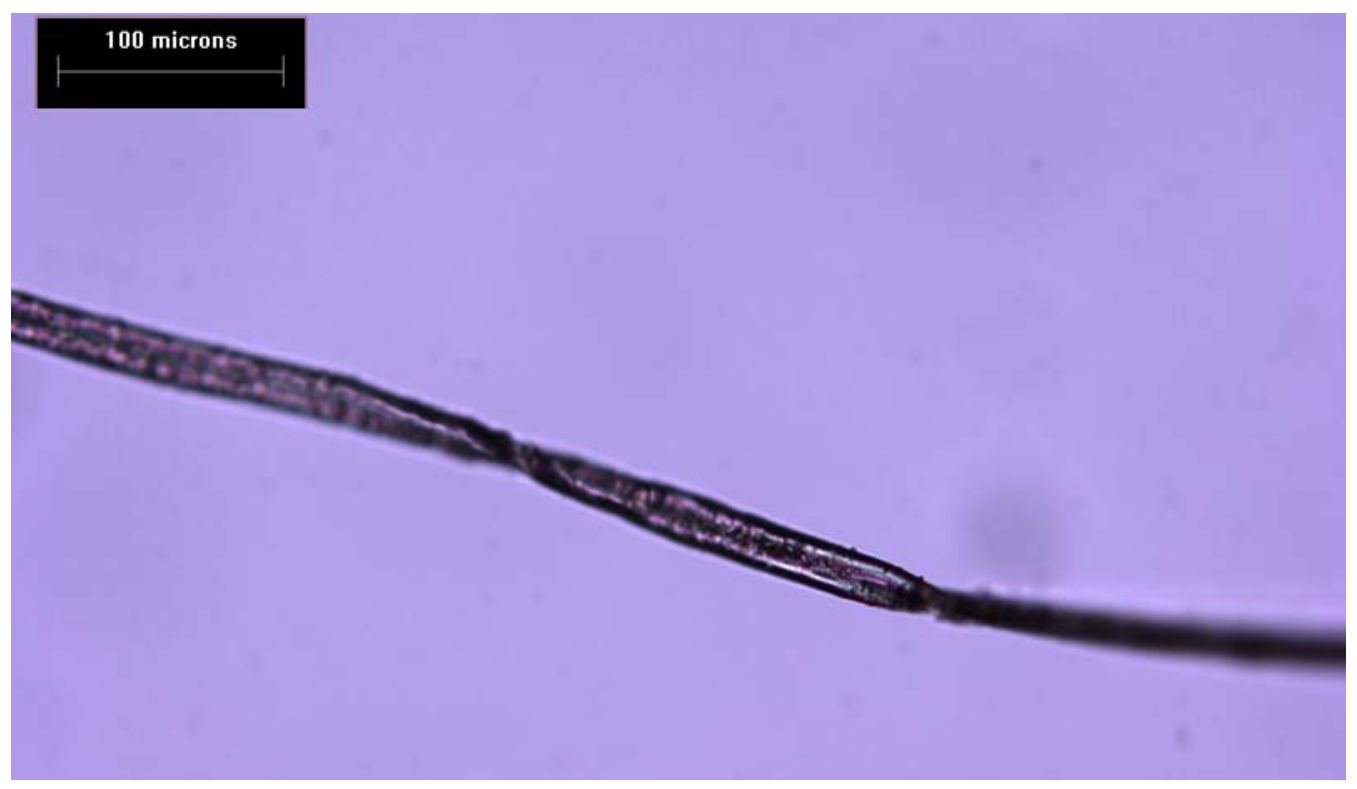

Figure 4 High-magnification image of a cotton fiber, crossed polars

\section{DISCUSSION}

Variations are going to be present in any hand-made textile, and small amounts of foreign materials are to be expected on any textile hundreds of years old. Before the strict storage conditions in which the Shroud of Turin is undoubtedly kept today, it was likely to have been exposed to mold, general debris, desiccating environments, and any other foreign matter present during early handling and preservation attempts that would have left some residue on the material. It is therefore not surprising to observe debris. This debris would have been removed by the various pretreatments used in Damon et al. (1989), which included standard acid-base-acid treatments, and ultrasonic cleaning in water or detergents for different fractions.

The presence of a few cotton fibers is not unusual. It is possible cotton fibers are present from wrapping the textile in a cotton cloth, a practice that is still used in textile storage. It is also possible that processing of the fibers or the loom contained remnants of cotton fibers, which contaminated the shroud. We can also state that the linen fibers observed in this study have only low levels of contamination by a few cotton fibers, consistent with the original observations on the shroud (e.g. Raes 1976) that there are a few cotton fibers on (or in) the shroud. 


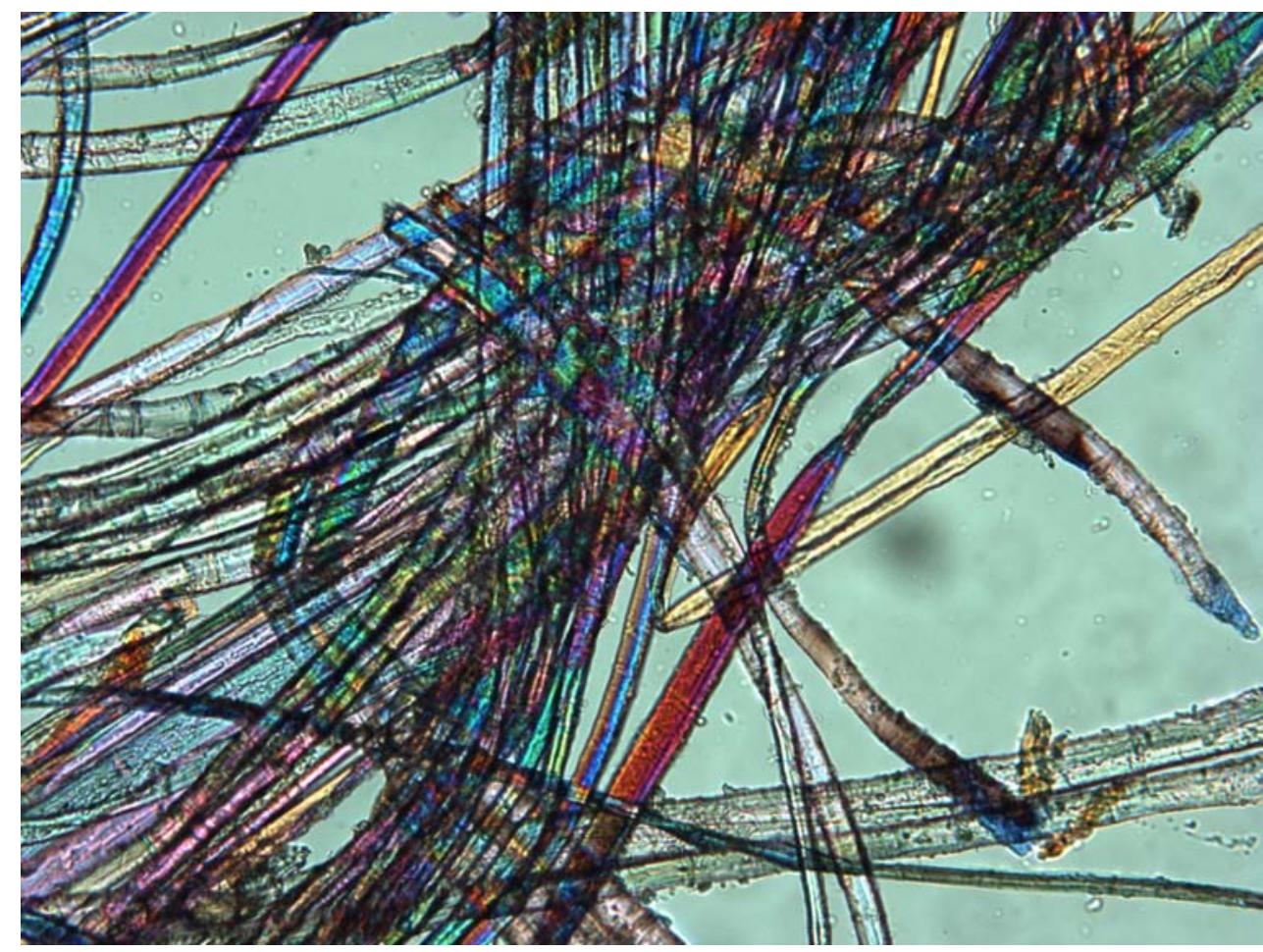

Figure 5 High-magnification image of a fiber bundle, showing the presence of a cotton fiber, unidentified fibers, and debris. This area appears to have been exposed to more contamination than other samples.

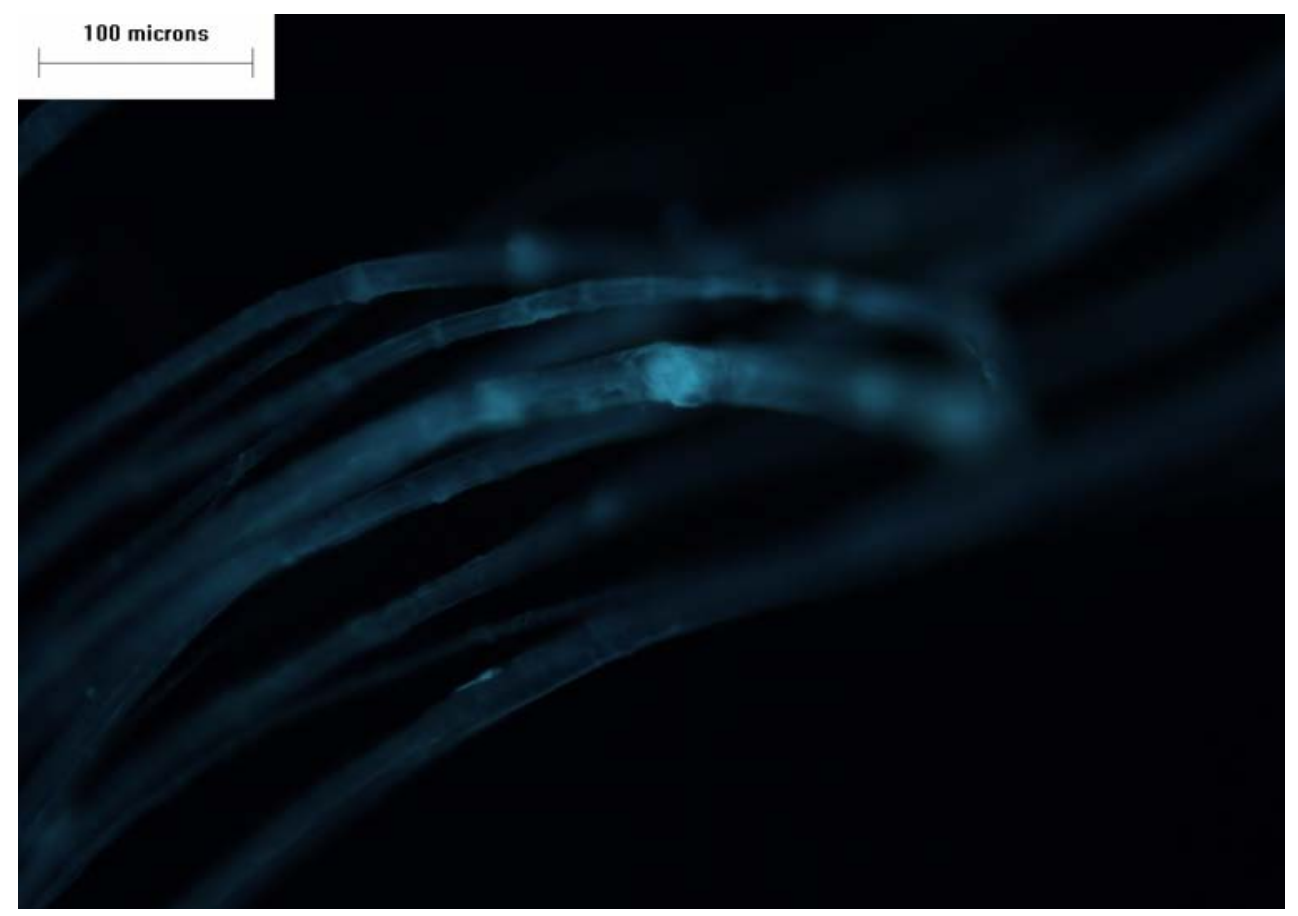

Figure 6 UV fluorescence image at high magnification of linen fibers, showing no evidence for any type of coating 


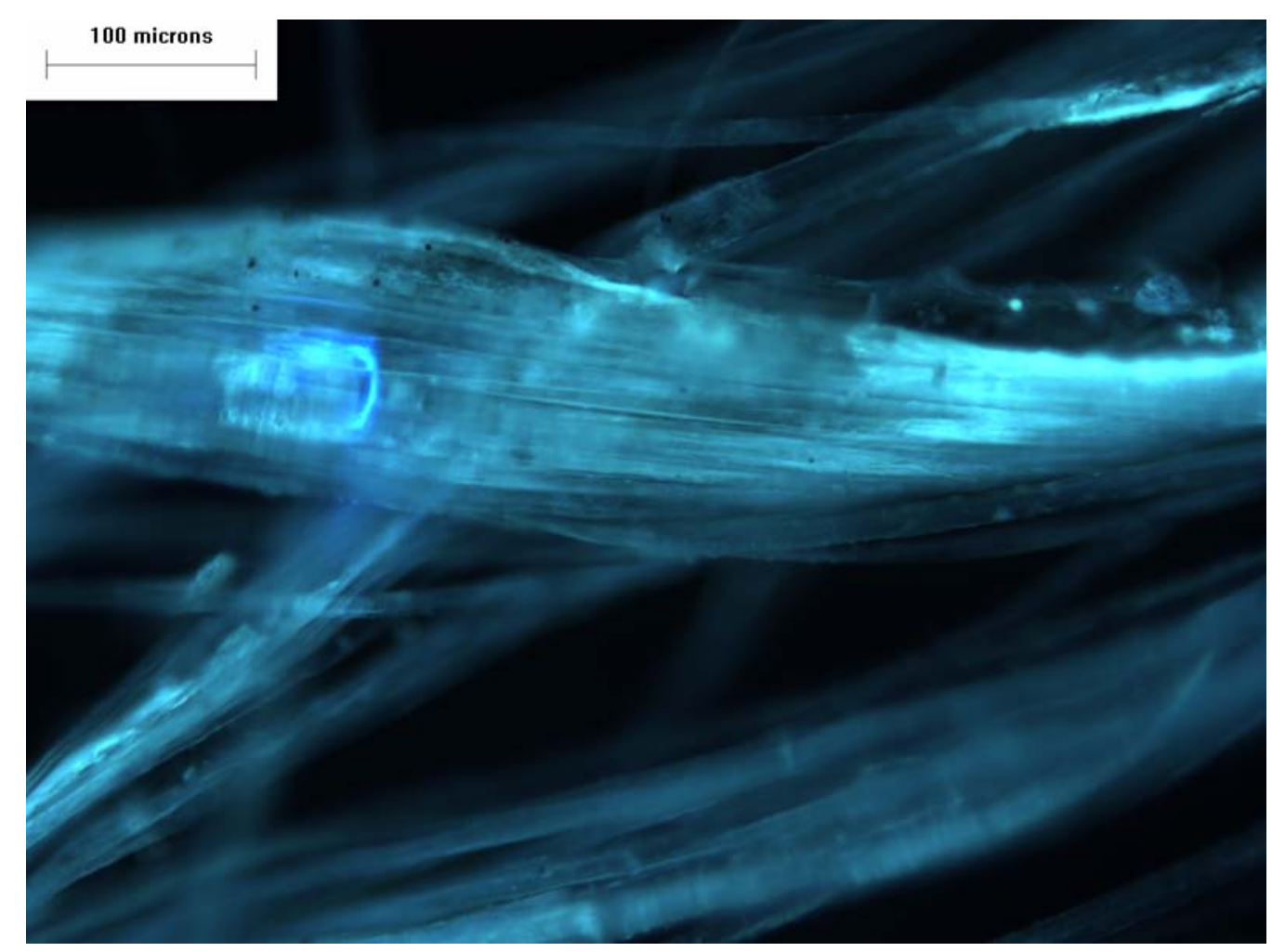

Figure 7 UV fluorescence image at high magnification of linen fibers, showing apparent mold spores

In addition, we find no evidence for any coatings or dyeing of the linen. Rogers (2005) suggested that the fibers in his study, which came from the Raes fragments (e.g. Heimberger 2009), were coated with a Madder root dye (e.g. alizarin) and mordant. Linen does not readily accept dye, and any surface "coating" would be loosely adhered. We viewed a textile fragment dyed using traditional methods under UV light, and observed absolutely no similarity in UV fluorescence consistent with such a dye. Rogers (2005) and others assert that the Raes and the "radiocarbon samples" he studied are dyed, in contrast to the main part of the shroud. As stated by Rogers (2005), "No other part of the shroud shows such a coating."

The sampling of the Shroud of Turin in 1988 is stated by those present (e.g. D J Donahue, personal communication, 2010) to have been taken "from the main part of the shroud." Those removing the samples at the time were aware of repair material. We conclude from our observations and the history of our sample, that our sample was taken from the main part of the shroud. There is no evidence to the contrary. We find no evidence to support the contention that the ${ }^{14} \mathrm{C}$ samples actually used for measurements are dyed, treated, or otherwise manipulated. Hence, we find no reason to dispute the original ${ }^{14} \mathrm{C}$ measurements, since our sample is a fragment cut on the arrival of the Arizona ${ }^{14} \mathrm{C}$ sample in Tucson on 24 April 1988 by coauthor Jull, and has been in his custody continuously.

We assume that there will be future studies on the Shroud of Turin. Any such future sampling should include another sample of the shroud away from the previous area sampled. In our opinion, such a study would be useful to confirm the previous results and should include both textile analysis and ${ }^{14} \mathrm{C}$ measurements. 
The following ASTM Textile Standards were referenced in this report:

- ASTM D3775;

- ASTM D1777.

\section{ACKNOWLEDGMENTS}

This work was done while R Freer was the Kress Conservation Fellow at the Arizona State Museum. We thank A Hedlund, D J Donahue, and D Killick for helpful discussions and R E Taylor for a review. The multifunctional laboratory at the Anthropology Department was supported from an NSF IGERT grant DGE-0221594. The work at the AMS Laboratory was supported in part by NSF grant EAR0622305.

\section{REFERENCES}

Benford MS, Marino J. 2008. Discrepancies in the radiocarbon dating area of the Turin Shroud. Chemistry Today $26: 4-12$.

Brown JL. 2005. Microscopical investigation of selected Raes threads from the Shroud of Turin. [WWW document]. http://www.shroud.com/pdfs/brown1.pdf. Accessed 30 March 2010.

Catling D, Grayson J. 1982. Identification of Vegetable Fibers. New York: Chapman and Hall.

Currie LA. 2004. The remarkable metrological history of radiocarbon dating [II]. Journal of Research of the $\mathrm{Na}$ tional Institute of Standards and Technology 109(2): 185-217.

Damon PE, Donahue DJ, Gore BH, Hatheway AL, Jull AJT, Linick TW, Sercel PJ, Toolin LJ, Bronk CR, Hall ET, Hedges REM, Housley R, Law IA, Perry C, Bonani G, Trumbore S, Wölfli W, Bowman SGE, Leese MN, Tite MS. 1989. Radiocarbon dating of the Shroud of Turin. Nature 337(6208):611-5.

Emery I. 1980. The Primary Structures of Fabric: An Illustrated Classification. Washington, DC: The Textile Museum.

Florian ME. 1990. Plant anatomy: an illustrated aid to identification. In: Florian ME, Kronkright DP, Norton RE, editors. The Conservation of Artifacts Made from
Plant Materials. Los Angeles: Getty Conservation Institute. p 1-27.

Garside P, Wyeth P. 2006. Identification of cellulosic fibers by FTIR spectroscopy: differentiation of flax and hemp by polarized ATR FTIR. Studies in Conservation 51(3):205-11.

Heimberger Th. 2009. Cotton in Raes/radiocarbon threads: the example of Raes \#7 [WWW document]. http://www.shroud.com/pdfs/thibaultr7part1.pdf. Accessed 30 March 2010

Morris RA, Schwalbe LA, London RJ. 1980. X-ray fluorescence investigation of the Shroud of Turin. X-Ray Spectrometry 9(2):40-7.

Raes G. 1976. Rapport d'Analise. La S. Sindone, supplement to Rivista Diocesana Torinese. p 79-83.

Rogers RN. 2005. Studies on the radiocarbon sample from the Shroud of Turin. Thermochimica Acta 425: 189-94.

Schwalbe LA, Rogers RN. 1982. Physics and chemistry of the Shroud of Turin: a summary of the 1978 investigation. Analytica Chimica Acta 135(1):3-49.

Tyrer J. 1981. Looking at the Turin Shroud as a textile. Textile Horizons. December, 1981. p 20-3.

Walsh JE. 1963. The Shroud of Turin. New York: Random House. 